Available online at http://jddtonline.info

RESEARCH ARTICLE

\title{
FABRICATION, DEVELOPMENT AND CHARACTERIZATION OF CARVEDILOL TRANSDERMAL PATCHES: AN EMPIRICAL STUDY
}

\author{
Sanjay K. Chourasiya ${ }^{* 1}$, Minakshi Verma ${ }^{3}$, T. Maity ${ }^{2}$, Ashish K. Gupta ${ }^{4}$, Renu Singh ${ }^{2}$, Vani Sharma ${ }^{2}$ \\ A. Mittal' ${ }^{2}$, K Gupta ${ }^{2}$, B C Nandy ${ }^{2}$ \\ ${ }^{1}$ Shri Ramnath Singh Mahavidyalaya (Pharmacy) Gormi, Bhind, MP, India \\ 2 Jayoti Vidyapeeth Women's University, Jaipur, Rajasthan, India \\ ${ }^{3}$ Department of Pharmacy, G.S.V.M., Medical College Kanpur, Uttar Pradesh, India. \\ ${ }^{4}$ Department of Pharmacy, V.B.S., Purvanchal University, Jaunpur, Uttar Pradesh, India. \\ * Corresponding author: Shri Ramnath Singh, Mahavidyalaya (Pharmacy) Gormi, Bhind, MP, India
}

Tel: +919993273571; E-mail: sanjay4488@gmail.com; Fax:+91 752786291

\begin{abstract}
Carvedilol is a nonselective beta-adrenergic blocking agent and is employed for the treatment of hypertension. Carvedilol is subjected to considerable first-pass metabolism when it is administered orally. Transdermal preparation of carvedilol was prepared to achieve a sustained effect and to reduce the dose size \& dosing frequency as compared to multiple oral dosing and also developed to minimize first pass metabolism. Various polymers such as Ethyl cellulose, PVP K-30, HPMC K15M and Carbopol 934 were selected on the basis of their adhering property and nature of non toxicity, to develop transdermal film of carvedilol. The patches fabricated by EC and Carbopol (F-5 and F-6) were showed very good folding endurance compared to patches containing PVP K-30 and HPMC K15M. Based on physicochemical and in-vitro permeation studies, F3 and F-5 were chosen as the best formulations. Among these two patches, F-5 film was found to have maximum in vitro permeation, maximum steady state flux and maximum permeability coefficient of drug.

Key words: Transdermal patch, Carvedilol, ethylcellulose, PVP K-30, HPMC K15M and Carbopol 934
\end{abstract}

\section{INTRODUCTION}

The budding interest and challenges in the delivery of active ingredients through skin has generated number of advancement throughout recent years with a focus on emerging novel application that offers many advantage such as reduced side effects, less frequent administration to produce the desired constant plasma concentration associated with patient compliance, elimination of the first pass effect, sustained drug delivery and interruption of treatment when necessary ${ }^{1-3}$.

Carvedilol is widely used for the therapeutic management of hypertension and congestive heart failure. It is drug of choice for hypertension but it has several drawbacks such as short biological half life (2-8 hours), readily metabolized in liver primarily by cytochrome P450 isoenzyme (CYP 206 and CYP 209) and has an oral bioavailability of 25-30\%. These factors in addition to its low molecular weight (406.05), low melting point $\left(117^{\circ} \mathrm{C}\right)$, high lipid solubility and effective in low plasma concentration necessitates the formulation of sustained release transdermal drug delivery system for carvedilol $^{2-4}$.

Polymers such as Ethyl cellulose, PVP K-30, HPMC K15M and Carbopol 934 were selected on the basis of their adhering property and non toxicity to prepare Carvedilol transdermal patches. Transdermal drug delivery system is a most suitable system for a long-term treatment. Transdermal patches are prepared for a long period of time in a suitable dose to provide the treatment from a day to even up to seven days. In this study Carvedilol transdermal patches were prepared with combination of different polymers such as EC: PVP K30, EC: HPMC K-15M, EC: Carbopol-934. Formulations were further evaluated on the basis of their physicochemical properties, in-vitro drug permeation study and surface $\mathrm{pH}$ of the film. Physicochemical evaluation like thickness, weight variation, moisture content, drug content, folding endurance and flatness of the prepared transdermal patches were checked. A best patch among all the formulations was chosen on the basis of some evaluating parameters like maximum permeation, steady state flux and permeability coefficient. The main objective of this current study was to develop a potentially competitive product by optimizing and screening of various formulations variables to deliver the drug at a controlled rate across the skin.

\section{MATERIAL \& METHODS}

Carvedilol, HPMC K4 M, PVP K30, Carbopol-934 were obtained as gift sample from Zydus Cadila, Ahmedabad, India. Ethyl cellulose, PEG 200, PVP and n-Octanol were procured from Cental Drug House (P) Ltd., Mumbai, India. Methanol, potassium dihydrogen phosphate, sodium chloride, chloroform were procured from Ranbaxy fine chemicals, Delhi, India.

\section{Determination of Partition Coefficient}


The partition coefficient study of pure drug was performed using $50 \mathrm{ml} \mathrm{n}$-octanol as the oil phase and 50 $\mathrm{ml}$ phosphate buffers (PH 6.8) as the aqueous phase ${ }^{5}$. The two phases were mixed in a separating funnel and were shaken continuously for $2 \mathrm{hrs}$ by adding $50 \mathrm{mg}$ of drug to achieve a complete partitioning of drug. The two phases were separated by centrifugation at $1500 \mathrm{rpm}$ for $5 \mathrm{~min}$ and the amounts of drug in both the phases were then analyzed spectrophotometrically at $242 \mathrm{~nm}$.

\section{Preparation of Transdermal Film}

Drug free films were prepared by using the solvent evaporation method $^{2,7,8}$. In our earlier published paper ${ }^{2}$ the preparation of carvidilol transdermel films were optimized. The lower part of the Petri dish was wrapped with aluminum foil on which the backing membrane was casted by pouring $5 \mathrm{ml}$ of $4 \%(\mathrm{w} / \mathrm{v})$ polyvinyl alcohol
(PVA) solution followed by drying at $60^{\circ} \mathrm{C}$ for $6 \mathrm{hr}$ in hot air oven. After drying the backing membrane, different polymers were mixed in chloroform containing PEG-200 (30\% (w/w) of total polymer composition) and $5 \mathrm{ml}$ of the polymer solution was poured in the Petridis and an inverted funnel was placed on the Petri dish to facilitate the evaporation of solvent at controlled manner. It was kept in an oven over a drying period of $6 \mathrm{hr}$ at $40^{\circ} \mathrm{C}$.The film was retrieved by cutting with surgical knife and kept in the desiccators for further evaluation. Drug loaded polymeric film was prepared in similar manner except that $16 \mathrm{mg}(2.5 \% \mathrm{w} / \mathrm{w}$ of total amount of polymers) of carvedilol dissolved in $5 \mathrm{ml}$ chloroform and it was added in the polymer solution containing plasticizer. Different formulations were prepared by using each polymer ratio of 6:4 and 8:2 of EC: PVP K30; EC: HPMC K15 and EC: Carbopol-934.

Table 1: Composition of Different Optimized drug loaded polymeric patches

\begin{tabular}{|c|c|c|c|c|c|c|c|}
\hline \multirow{2}{*}{$\begin{array}{l}\text { S. } \\
\text { No. }\end{array}$} & \multirow[t]{2}{*}{ Ingredients } & \multicolumn{6}{|c|}{ Formulations Code No. } \\
\hline & & F1 & F2 & F3 & F4 & F5 & F6 \\
\hline 1. & Ethyl cellulose (EC) & $374.4 \mathrm{mg}$ & $499.2 \mathrm{mg}$ & $374.4 \mathrm{mg}$ & $499.2 \mathrm{mg}$ & $374.4 \mathrm{mg}$ & $499.2 \mathrm{mg}$ \\
\hline 2. & $\begin{array}{l}\text { Polyvinyl pyrrolidone K-30 } \\
\text { (PVP K-30) }\end{array}$ & $249.6 \mathrm{mg}$ & $124.8 \mathrm{mg}$ & - & - & - & - \\
\hline 3. & $\begin{array}{l}\text { Hydroxypropyl methylcellulose } \mathrm{K} 15 \mathrm{M} \\
\text { (HPMCK15M) }\end{array}$ & - & - & $249.6 \mathrm{mg}$ & $124.8 \mathrm{mg}$ & - & - \\
\hline 4. & Carbopol- 934 & - & - & - & - & $249.6 \mathrm{mg}$ & $124.8 \mathrm{mg}$ \\
\hline 5. & $\begin{array}{l}\text { Carvedilol }(2.5 \% \mathrm{w} / \mathrm{w} \text { of total polymer } \\
\text { composition) }\end{array}$ & $16 \mathrm{mg}$ & $16 \mathrm{mg}$ & $16 \mathrm{mg}$ & $16 \mathrm{mg}$ & $16 \mathrm{mg}$ & $16 \mathrm{mg}$ \\
\hline 6. & $\begin{array}{l}\text { PVA }(4 \% \text { w/v of total polymer } \\
\text { composition })\end{array}$ & $5 \mathrm{ml}$ & $5 \mathrm{ml}$ & $5 \mathrm{ml}$ & $5 \mathrm{ml}$ & $5 \mathrm{ml}$ & $5 \mathrm{ml}$ \\
\hline 7. & $\begin{array}{l}\text { PEG-200 (30\% w/v of total polymer } \\
\text { composition) }\end{array}$ & $0.2 \mathrm{ml}$ & $0.2 \mathrm{ml}$ & $0.2 \mathrm{ml}$ & $0.2 \mathrm{ml}$ & $0.2 \mathrm{ml}$ & $0.2 \mathrm{ml}$ \\
\hline 8. & Chloroform & $15 \mathrm{ml}$ & $15 \mathrm{ml}$ & $15 \mathrm{ml}$ & $15 \mathrm{ml}$ & $15 \mathrm{ml}$ & $15 \mathrm{ml}$ \\
\hline
\end{tabular}

\section{Evaluations of transdermal patches}

\section{Thickness:}

The thickness ${ }^{9}$ of the each patch was measured using screw gauge at different positions of the patch and the average was calculated.

\section{Weight variation:}

Weight variation ${ }^{10}$ was studied by individually weighing 10 randomly selected patches $\left(46.57 \mathrm{~cm}^{2}\right)$. Such determination was performed for each formulation.

\section{Folding endurance:}

Folding endurance ${ }^{11,12}$ was determined by repeatedly folding one film at the same place till it broke. The number of times the film could be folded at the same place without breaking/ cracking gave the value of folding endurance.

\section{Moisture content:}

The patches were weighed ${ }^{10-12}$ individually and kept in a desiccators containing activated silica at room temperature for $24 \mathrm{~h}$. Then, the final weight was noted when there was no further change in the weight of the individual patch. The percentage of moisture content was calculated as a difference between initial and final weight with respect to final weight.

\section{Drug content uniformity:}

Three longitudinal strips were collected by cutting off three zones from each film: one from the centre, one from the left side and one from the right side ${ }^{11}$. Patches of $0.64 \mathrm{~cm}^{2}$ areas from each zone were dissolved in 200 $\mathrm{ml}$ of methanol and the volume was made up to $100 \mathrm{ml}$ with same solvent and placed on electronic shaker for $1 \mathrm{~h}$ to dissolve completely patches in methanol. The solutions were filtered through a $0.45 \mu \mathrm{m}$ membrane, diluted suitably and absorbance were noted at $242 \mathrm{~nm}$ in a double beam UV-Visible spectrophotometer (Model1700, Shimadzu, Japan) against a blank that was prepared using a drug-free patch treated similarly after that drug content was calculated.

\section{Flatness study:}

Three longitudinal strips were collected by cutting off three zones from each film: one from the centre, one from the left side and one from the right side. The length of each strip was measured and the variation in length because of non-uniformity in flatness ${ }^{11,12}$ was measured 
by determining percent constriction, with $0 \%$ constriction equivalent to $100 \%$ flatness.

$$
\% \text { Constriction }=\left[\left(1_{1}-l_{2}\right) / l_{2}\right] \times 100
$$

Where, $1_{1}=$ initial length of each strip

$$
1_{2}=\text { final length of each strip }
$$

\section{Drug and Polymers compatibility studies \\ Differential Scanning Calorimetry:}

The physicochemical compatibility between Carvedilol and polymers used in the patches was further studied by using differential scanning calorimetry (DSC Q10 V9.4 Build 287, TA Instruments, USA). In DSC analysis, the samples were weighed $(2 \mathrm{mg})$, hermetically sealed in flat-bottom aluminum pans, and heated over a temperature range of 50 to $150^{\circ} \mathrm{C}$ and 50 to $250^{\circ} \mathrm{C}$ in an atmosphere of nitrogen $(50 \mathrm{~mL} / \mathrm{min})$ at a constant increasing rate of $10^{\circ} \mathrm{C} / \mathrm{min}$. The Thermograms obtained for Carvedilol, polymers and formulations of Carvedilol with polymers were compared ${ }^{13}$.

\section{Fourier Transformed Infrared Spectroscopy:}

The drug loaded transdermal film was analyzed by FTIR ${ }^{13}$ to confirm the chemical interaction between the drug and polymer using the thin film. IR spectrums were scanned on a model, RX-I FT-IR system, Perkin Elmer, USA in the range of $450-4000 \mathrm{~cm}^{-1}$.

\section{X-ray diffraction studies:}

X-ray diffraction studies were carried on physical mixture and drug containing transdermal film using the XRD technique 14-16 with model X'Pert-Pro diffractometer system PANalytical, The Netherlands. XRD studies were performed on the samples by expose them to $\mathrm{Cu} \mathrm{K}-\alpha-1$ radiation $(45 \mathrm{kV}, 40 \mathrm{~mA})$ and scanned from 2 to $50^{\circ} 2 \theta$, at a step size of $0.01702 \theta$ and a step time of $20.0271 \mathrm{~s}$.

\section{Surface pH of the Film}

Transdermal patches were allowed to swell for $2 \mathrm{~h}$ at $37^{\circ} \mathrm{C}$ on the surface of an agar plate, prepared by dissolving $2 \%(\mathrm{w} / \mathrm{v})$ agar in worm isotonic phosphate buffer of $\mathrm{pH} 5.5$ under stirring and then pouring the solution into a Petri dish till gelling at room temperature. The surface $\mathrm{pH}$ was measured by means of a $\mathrm{pH}$ paper placed on the surface of the swollen patch. The mean of six reading was recorded.

\section{In-vitro Permeation Studies}

In vitro skin permeation studies ${ }^{16-18}$ were performed by using a Franz diffusion cell with a receptor compartment capacity of $50 \mathrm{ml}$. The excised rat abdominal skin was mounted between the donor and receptor compartment of the diffusion cell. The formulated patches were placed over the skin and covered with paraffin film. The receptor compartment of diffusion cell was filled with phosphate buffer $\mathrm{pH}$ 7.4. The whole assembly was fixed on a magnetic stirrer and the solution in the receptor compartment was constantly and continuously stirred using magnetic beads at $50 \mathrm{rpm}$; the temperature was maintained at $37 \pm 0.5^{\circ} \mathrm{C}$. The $2 \mathrm{ml}$ aliquots were withdrawal at different time intervals $(0,30,60,90,120$, 150 and $24 \mathrm{~h}$ ) and analyzed for drug content spetrophotometrically by UV-Visible spectrophotometer (Model-1700, Shimadzu, Japan) at $242 \mathrm{~nm}$. The receptor phase was replenished with an equal volume of phosphate buffer $\left(37^{\circ} \mathrm{C}\right)$ at each sample withdrawal, the cumulative amount of drug permeated per square centimeter of patches were plotted against time.

\section{Scanning Electron Microscopy (SEM)}

Sample, for the SEM ${ }^{18}$ was prepared by sprinkling the film on one side of a double adhesive stub. The stub was then coated with gold under vacuum (Fine Coat, in sputter, EC-1100). The transdermal patches were then observed under the scanning electron microscope (JEOL, JSM-6360 Scanning Electron Microscope, Japan) at $15 \mathrm{Kv}$. The samples include blank film (without drug), film before and after carrying out the permeation studies.

\section{Stability Studies}

Accelerated stability testing was conducted for 30 days at different temperatures: 4,45 , and $60^{\circ} \mathrm{C}$. At specific intervals of time (Day 5, 10, 15, 20, 25, and 30), patches were taken out to assay their drug content, appearance, and texture.

\section{RESULTS AND DISCUSSION}

The partition coefficient of pure drug was proved its lipophilic characteristic and carvidilol is suitable to design a transdermal drug delivery system. The thicknesses for various formulations ranged between $0.09 \pm 0.012 \mathrm{~mm}$ to $0.21 \pm 0.020 \mathrm{~mm}$ and which are tabulated in table 2. The deviation in the thickness was within the limits, as it gets confirmed by lower values of standard deviation. F-3 and F-4 formulations were prepared by EC and HPMC K15M and it has been seen with increases of HPMC content thickness was increased consistently but which was not observed in case of formulations fabricated by EC: Carbopol 934. It may be due to the gel forming properties of Carbopol, where as PVP do not contribute significantly towards thickness building as compared to HPMC and Carbopol. 
Table 2: Physicochemical Characteristics of Transdermal Patches

\begin{tabular}{|c|c|c|c|c|c|c|c|c|c|}
\hline $\begin{array}{c}\text { Formulation } \\
\text { Code No. }\end{array}$ & $\begin{array}{c}\text { Polymers } \\
\text { Used }\end{array}$ & $\begin{array}{c}\text { Ratio } \\
\text { of } \\
\text { Polymer }\end{array}$ & $\begin{array}{c}\text { Thickness } \\
\text { (mm) } \\
\text { Mean } \pm \\
\text { S.D. }\end{array}$ & $\begin{array}{c}\text { Weight } \\
\text { (mg) } \\
(46.57 \\
\left.\mathrm{cm}^{2}\right) \\
\text { Mean } \pm \\
\text { S.D. }\end{array}$ & $\begin{array}{c}\text { Folding } \\
\text { Endurance }\end{array}$ & $\begin{array}{c}\text { Moisture } \\
\text { Content } \\
(\%)\end{array}$ & $\begin{array}{c}\text { Drug } \\
\text { Content } \\
(\mathrm{mg}) \\
\left(0.64 \mathrm{~cm}^{2}\right) \\
\text { Mean } \pm \\
\text { S.D. }\end{array}$ & $\begin{array}{c}\text { Flatness } \\
(\%)\end{array}$ & $\begin{array}{c}\text { Surface } \\
\text { pH }\end{array}$ \\
\hline F-1 & $\begin{array}{c}\text { EC:PVP } \\
\text { K-30 }\end{array}$ & $6: 4$ & $\begin{array}{c}0.09 \pm \\
0.012\end{array}$ & $\begin{array}{c}840 \pm \\
0.75\end{array}$ & $>16$ & $4.21 \pm 3.4$ & $\begin{array}{c}0.232 \pm \\
0.021\end{array}$ & 100 & $\approx 6-7$ \\
\hline F-2 & $\begin{array}{c}\text { EC:PVP } \\
\text { K-30 }\end{array}$ & $8: 2$ & $\begin{array}{c}0.10 \pm \\
0.013\end{array}$ & $\begin{array}{c}839 \pm \\
0.92\end{array}$ & $>14$ & $3.17 \pm 2.1$ & $\begin{array}{c}0.219 \pm \\
0.018\end{array}$ & 100 & $\approx 6-7$ \\
\hline F-3 & $\begin{array}{c}\text { EC:HPMC } \\
\text { K15M }\end{array}$ & $6: 4$ & $\begin{array}{l}0.21 \pm \\
0.014\end{array}$ & $\begin{array}{l}840.7 \\
\pm 1.62 \\
\end{array}$ & $>10$ & $5.06 \pm 2.4$ & $\begin{array}{c}0.212 \pm \\
0.011\end{array}$ & 100 & $\approx 6-7$ \\
\hline F-4 & $\begin{array}{c}\mathrm{EC}: \mathrm{HPMC} \\
\mathrm{K} 15 \mathrm{M}\end{array}$ & $8: 2$ & $\begin{array}{l}0.21 \pm \\
0.020\end{array}$ & $\begin{array}{c}840.9 \pm \\
1.52\end{array}$ & $>8$ & $4.12 \pm 2.9$ & $\begin{array}{c}0.210 \pm \\
0.031\end{array}$ & 100 & $\approx 6-7$ \\
\hline F-5 & EC:CP-934 & $6: 4$ & $\begin{array}{l}0.11 \pm \\
0.016\end{array}$ & $\begin{array}{c}840.5 \pm \\
2.43\end{array}$ & $>50$ & $5.68 \pm 3.4$ & $\begin{array}{c}0.227 \pm \\
0.043\end{array}$ & 100 & $\approx 5-6$ \\
\hline F-6 & $\begin{array}{c}\text { EC: CP- } \\
934\end{array}$ & $8: 2$ & $\begin{array}{c}0.11 \pm \\
0.014\end{array}$ & $\begin{array}{c}840.4 \pm \\
1.46\end{array}$ & $>50$ & $4.79 \pm 2.2$ & $\begin{array}{c}0.223 \pm \\
0.025\end{array}$ & 100 & $\approx 5-6$ \\
\hline
\end{tabular}

The total weight for various formulations ranged between $839 \pm 0.92$ to $840.9 \pm 1.52 \mathrm{mg}$ (table 2). The deviation in the weight was within the limits as it gets confirmed by lower values of standard deviation (table 2 ). It was observed that the weight of the patches was increasing gradually with increase of HPMC content. The weight of the patches increased with increase in thickness of the respective patches the thickness of the patches were increased. The total weight of patches in $\mathrm{mg} / 46.57 \mathrm{~cm}^{2}$ was shown in table 2 .

The values of the folding endurance for all the formulations are tabulated in table 2. The F-1 and F-2 patches fabricated by EC and PVP K-30 showed a folding endurance of more than 16 and 14 respectively. The F-3 and F-4 patches prepared by EC and HPMC $\mathrm{K} 15 \mathrm{M}$ showed folding endurance more than 10 and 8 respectively. In comparison with patches made by EC: PVP K-30 and EC: HPMC K15M, the patches (F-5 and F-6) made of EC and Carbopol showed folding endurance more than 50 . It can be concluded that the patches made of Carbopol were shown better folding endurance compared to patches containing PVP K-30 and HPMC K15M.

Moisture content studies indicated that the increase in the concentration of hydrophilic polymer was directly proportional to the increase in moisture content of the patches. Moisture content of F-1 and F-2 patches were found in the range of $3.17 \pm 2.1$ to $4.21 \pm 3.4 \%$ (table 2), which showed least moisture content compared to other patches. Moisture content of F-3 and F-4 patches were found in the range of $4.12 \pm 2.9$ to $5.06 \pm 2.4 \%$, which having higher level of moisture content compared to F-1 and F-2 patches; that may be due to presence of hydrophilic nature of HPMC K15M polymer. The moisture content of F-5 and F-6 patches was found in the range of $4.79 \pm 2.2$ to $5.68 \pm 3.4 \%$; which having greater moisture content in comparison to other patches, due to presence of more hydrophilic nature of Carbopol 934. The moisture content of the prepared formulations was low, which could help the formulations remain stable and reduce brittleness during long term storage and this could protect the formulations from microbial contamination and reduce bulkiness.
For all the formulations, the drug content in area of 0.64 $\mathrm{cm}^{2}$ was determined and it was shown in between the range of $0.210 \pm 0.031$ to $0.232 \pm 0.021 \mathrm{mg}$ and which was tabulated in table 2 . The drug content of all the prepared formulations shown that the process employed to prepare transdermal patches was capable of giving a uniform distribution of drug throughout the whole patches and showed minimum batch variability.

The flatness study showed that all the formulations had the same strip length before and after their cuts, indicating $100 \%$ flatness (table 2). Thus all patches had a smooth, flat surface; no constriction and that smooth surface could be maintained when the patch was applied to the skin.

\section{Surface pH of the Film:}

The surface $\mathrm{pH}$ of the polymeric patches ranged between 5 to 7 (table 2) which falls within the $\mathrm{pH}$ range of skin i.e. 4.0-6.5. Further, the surface $\mathrm{pH}$ data revealed that upon increase in Carbopol concentration the surface $\mathrm{pH}$ of the formulation decreased gradually. Some researchers 16-18 suggested that excess concentration of Carbopol in the formulation may cause irritation to the skin due to its acidic nature. That is why formulation containing Carbopol, its concentration should be optimized and it was further confirmed by conducting the skin irritation studies.

\section{In-Vitro Skin Permeation Study:}

Release of the drug from transdermal patches is dependent on the physico-chemical properties of the drug and physiological \& physicochemical properties of the biological membrane. In vitro skin permeation experiments are known for their value for studying the rate and mechanism of percutaneous absorption of drugs. In this experiment, variable permeation profiles of Carvedilol from the different experimental transdermal patches $\left(0.64 \mathrm{~cm}^{2}\right)$ compared with various blends of different polymers like EC, PVP K-30, HPMC K-15M and Carbopol-934. The percent of drug permeated after $24 \mathrm{~h}$ of the experiments was found between the ranges of $69.54 \%$ to $95.44 \%$ (table 3 ). The percent of drug permeated after $24 \mathrm{~h}$ was found to be maximum $95.44 \%$ 
and $90.12 \%$ from formulation F-5 and F-3 respectively (table 3). The process of drug release in most of the controlled release device is governed by diffusion and the polymer matrix has a strong influence of the diffusivity as the motion of small molecules is restricted by the three-dimensional network of polymer chains. The alteration of the cross linking and the modification of structural arrangements of polymers by using different blends of polymers already reported. So, different drug permeation profiles from various formulations could be attributable to the varied cross linking networks of polymeric chains of the different blends of polymeric transdermal experimental formulations as tortuosity and diffusion pathway varied, and they thereby have been reported to vary the release of drug and duration of diffusion.

Table 3: Percentage (w/w) drug permeated through the rat skin from various transdermal Patches (F-1 to F-6)

\begin{tabular}{|c|c|c|c|c|c|c|c|}
\hline \multirow{2}{*}{$\begin{array}{c}\text { Time } \\
(\mathbf{m i n})\end{array}$} & $\begin{array}{c}\text { SQRT } \\
(\mathbf{m i n})\end{array}$ & \multicolumn{7}{|c|}{$\begin{array}{c}\text { \% Drug Permeated (mg) } \\
\text { (Mean } \pm \text { S.D. })\end{array}$} \\
\cline { 3 - 8 } & & $\mathbf{F - 1}$ & $\mathbf{F - 2}$ & $\mathbf{F - 3}$ & F-4 & F-5 & F-6 \\
\hline $\mathbf{0}$ & 0 & $0.000 \pm 0.00$ & $0.000 \pm 0.00$ & $0.000 \pm 0.00$ & $0.000 \pm 0.00$ & $0.000 \pm 0.00$ & $\mathbf{0 . 0 0 0} \pm \mathbf{0 . 0 0}$ \\
\hline $\mathbf{3 0}$ & 5.47 & $9.191 \pm 1.19$ & $8.042 \pm 0.64$ & $13.096 \pm 0.82$ & $10.821 \pm 0.72$ & $14.035 \pm 2.34$ & $\mathbf{1 1 . 0 9 5} \pm \mathbf{0 . 3 1}$ \\
\hline $\mathbf{6 0}$ & 7.74 & $16.197 \pm 2.18$ & $14.157 \pm 1.22$ & $20.038 \pm 0.61$ & $17.075 \pm 1.14$ & $20.043 \pm 1.98$ & $\mathbf{1 8 . 4 8 2} \pm \mathbf{0 . 7 8}$ \\
\hline $\mathbf{9 0}$ & 9.48 & $21.067 \pm 0.12$ & $19.777 \pm 0.65$ & $26.090 \pm 0.32$ & $21.856 \pm 0.57$ & $27.011 \pm 1.06$ & $\mathbf{2 3 . 6 3 4 \pm 0 . 7 0}$ \\
\hline $\mathbf{1 2 0}$ & 10.95 & $26.217 \pm 0.31$ & $26.802 \pm 0.26$ & $32.001 \pm 0.52$ & $26.901 \pm 0.43$ & $33.056 \pm 0.54$ & $\mathbf{2 8 . 6 3 4} \pm \mathbf{0 . 5 6}$ \\
\hline $\mathbf{1 5 0}$ & 12.24 & $29.189 \pm 0.75$ & $30.017 \pm 0.82$ & $34.014 \pm 0.61$ & $30.955 \pm 0.72$ & $35.1 \pm 0.87$ & $\mathbf{3 2 . 0 9 9} \pm \mathbf{0 . 4 5}$ \\
\hline $\mathbf{3 6 0}$ & 18.97 & $45 \pm 0.23$ & $40.877 \pm 0.25$ & $50.080 \pm 0.85$ & $45.736 \pm 0.34$ & $52.00 \pm 0.92$ & $\mathbf{4 7 . 2 9 6} \pm \mathbf{0 . 9 9}$ \\
\hline $\mathbf{1 4 4 0}$ & 37.94 & $80.916 \pm 1.81$ & $69.546 \pm 0.57$ & $90.127 \pm 0.87$ & $76.835 \pm 0.84$ & $95.441 \pm 1.00$ & $\mathbf{8 1 . 9 5 7} \pm \mathbf{0 . 8 8}$ \\
\hline
\end{tabular}

Table 4: Log percentage (w/w) of drug remaining to permeate through the rat skin from various Transdermal Patches (F-1 to F-6)

\begin{tabular}{|c|c|c|c|c|c|c|c|}
\hline \multirow{2}{*}{$\begin{array}{c}\text { Time } \\
(\mathbf{m i n})\end{array}$} & \multirow{2}{*}{$\begin{array}{c}\text { SQRT } \\
(\mathbf{m i n})\end{array}$} & \multicolumn{7}{|c|}{$\begin{array}{c}\text { Log (\%DRP) (mg) } \\
\text { (Mean } \pm \text { S.D. })\end{array}$} \\
\cline { 3 - 8 } & & F-1 & F-2 & F-3 & F-4 & F-5 & F-6 \\
\hline $\mathbf{0}$ & 0 & $0.000 \pm 0.00$ & $0.000 \pm 0.00$ & $0.000 \pm 0.00$ & $0.000 \pm 0.00$ & $0.000 \pm 0.00$ & $\mathbf{0 . 0 0 0} \pm \mathbf{0 . 0 0}$ \\
\hline $\mathbf{3 0}$ & 5.47 & $1.958 \pm 0.07$ & $1.963 \pm 0.02$ & $1.939 \pm 0.07$ & $1.950 \pm 0.08$ & $1.939 \pm 0.01$ & $\mathbf{1 . 9 4 8} \pm \mathbf{0 . 0 2}$ \\
\hline $\mathbf{6 0}$ & 7.74 & $1.923 \pm 0.06$ & $1.933 \pm 0.02$ & $1.902 \pm 0.06$ & $1.918 \pm 0.07$ & $1.902 \pm 0.02$ & $\mathbf{1 . 9 1 1} \pm \mathbf{0 . 0 9}$ \\
\hline $\mathbf{9 0}$ & 9.48 & $1.897 \pm 0.06$ & $1.904 \pm 0.03$ & $1.868 \pm 0.07$ & $1.892 \pm 0.09$ & $1.868 \pm 0.07$ & $\mathbf{1 . 8 8 4} \pm \mathbf{0 . 0 7}$ \\
\hline $\mathbf{1 2 0}$ & 10.95 & $1.867 \pm 0.02$ & $1.864 \pm 0.04$ & $1.832 \pm 0.04$ & $1.863 \pm 0.08$ & $1.832 \pm 0.09$ & $\mathbf{1 . 8 5 3} \pm \mathbf{0 . 0 1}$ \\
\hline $\mathbf{1 5 0}$ & 12.24 & $1.850 \pm 0.02$ & $1.844 \pm 0.05$ & $1.819 \pm 0.03$ & $1.839 \pm 0.02$ & $1.819 \pm 0.05$ & $\mathbf{1 . 8 3 1} \pm \mathbf{0 . 0 2}$ \\
\hline $\mathbf{3 6 0}$ & 18.97 & $1.740 \pm 0.04$ & $1.771 \pm 0.02$ & $1.698 \pm 0.04$ & $1.734 \pm 0.06$ & $1.698 \pm 0.06$ & $\mathbf{1 . 7 2 1} \pm \mathbf{0 . 0 2}$ \\
\hline $\mathbf{1 4 4 0}$ & 37.94 & $1.280 \pm 0.02$ & $1.483 \pm 0.01$ & $0.994 \pm 0.05$ & $1.364 \pm 0.06$ & $0.994 \pm 0.01$ & $\mathbf{1 . 2 5 6} \pm \mathbf{0 . 0 1}$ \\
\hline
\end{tabular}

In in-vitro skin permeation experiments also shown as the concentration of hydrophilic was increased, the amount of drug permeated was concurrently increased. This may be a result of the initial rapid dissolution of the hydrophilic polymers when the patch is in contact with the hydrated skin, which results in accumulation of high amount of drugs on the skin surface and thus leads to the saturation of the skin with drug molecules at all time. The rapid dissolution of the aqueous soluble fraction of the film also leads to the formation of pores, and hence higher release rate.

\section{Kinetic Release studies:}

To examine the drug permeation kinetics and mechanism, the data were fitted to models representing zero-order; first-order, Higuchi and Koresmeyer-Peppas. Release of the drug from a transdermal drug delivery system mainly involves the factor of diffusion. Diffusion is related to the transport of the drugs from a dosage matrix into the in vitro study fluid, depending on the concentration. As the gradient varies, the drug is released and the distance for diffusion becomes increasingly greater. This could be an explanation as to why the drug diffuses at a slower rate as the distance for diffusion increases. The kinetic parameters of drug permeation for different formulations were presented in table 5. In this experiments the in vitro permeation profiles of all formulations did not fit into zero-order $\left(\mathrm{R}^{2}=0.8754\right.$ to $0.9355)$ rather they could be best expressed by the firstorder (0.9593 to 0.9977) and Higuchi model $\left(\mathrm{R}^{2}=0.979\right.$ to 0.9919$)$. The permeation of drug from a homogenouspolymer matrix type delivery system was mostly depended on diffusion characteristics. The percent of drug permeated in $24 \mathrm{~h}$ was found to be maximum $95.44 \%$ and $90.12 \%$ from formulations F-5 and F-3 respectively. It has been confirm from the table 5 , that permeation of drug from patches followed both first order $\left(\mathrm{R}^{2}=0.9975\right.$ and 0.9977$)$ and Higuchi model $\left(\mathrm{R}^{2}=\right.$ 0.9909 and 0.9869). The data was further treated as per the following equation for confirming the KoresmeyerPeppas model: 


$$
\mathrm{M}_{\mathrm{t}} / \mathrm{M}_{\alpha}=\mathrm{K} \cdot \mathrm{t}^{\mathrm{n}}
$$

Where, $M_{t} / M_{\alpha}$, is the fractional release of drug, $M_{t}$ is the amount released at time $t, M_{\alpha}$ is the total amount of drug contained in the transdermal film, $\mathrm{t}$ is the release time, $\mathrm{K}$ is a kinetic constant and $\mathrm{n}$ is the diffusional release exponent indicative of the release mechanism. For Film $\mathrm{F}-3(\mathrm{n}=0.489)$ and F-5 $(\mathrm{n}=0.492)$ has $\mathrm{n}$ value near to 0.5 , it means drug permeation followed Fickian diffusion mechanism. $\mathrm{n}=0.5$ stands for Fickian diffusion; and all the other patches were also followed Fickian diffusion mechanism. When the permeability coefficients (table 6) of the different formulations were compared, only F-5 formulation showed maximum permeability coefficient compared to other formulations and the highest level of drug permeation through the rat skin. Based on physicochemical and in vitro permeation experiments, F3 and F-5 chosen for best film, but only F-5 formulation was found to have maximum rate of permeation (tables 4 \& 5), maximum steady state flux and maximum permeability coefficient (table 6) compared to the formulation F-3.

Table 5: Kinetics Models of In Vitro Carvedilol Permeation across Rat Skin from Transdermal Patches

\begin{tabular}{|c|c|c|c|c|c|c|c|c|c|}
\hline \multirow[t]{2}{*}{$\begin{array}{l}\text { Formulation } \\
\text { Code }\end{array}$} & \multicolumn{2}{|c|}{ Zero-Order } & \multicolumn{2}{|c|}{ First-Order } & \multicolumn{2}{|c|}{ Higuchi Model } & \multicolumn{3}{|c|}{$\begin{array}{c}\text { Koresmeyer-Peppas } \\
\text { Model }\end{array}$} \\
\hline & $\mathrm{k}_{0}\left(\mathrm{mg} \cdot \mathrm{min}^{-1}\right)$ & $\mathbf{R}^{2}$ & $\mathbf{k}_{1}\left(\min ^{-1}\right)$ & $\mathbf{R}^{2}$ & $\mathrm{k}_{2}(\underset{1 / 2}{\text { mg.min }})$ & $\mathbf{R}^{2}$ & $\mathbf{N}$ & $\mathbf{k}_{3}$ & $\mathbf{R}^{2}$ \\
\hline F-1 & 0.0459 & 0.9223 & 0.00115 & 0.9911 & 2.1977 & 0.9919 & 0.547 & 0.0211 & 0.9752 \\
\hline F-2 & 0.0381 & 0.8754 & 0.00069 & 0.9593 & 1.9632 & 0.9664 & 0.5397 & 0.0237 & 0.938 \\
\hline F-3 & 0.0493 & 0.9287 & 0.00161 & 0.9977 & 2.4942 & 0.9869 & 0.489 & 0.0307 & 0.9852 \\
\hline F-4 & 0.042 & 0.9029 & 0.00092 & 0.9799 & 2.1583 & 0.979 & 0.502 & 0.0291 & 0.9799 \\
\hline F-5 & 0.0526 & 0.9355 & 0.00207 & 0.9975 & 2.6172 & 0.9909 & 0.4922 & 0.0297 & 0.9885 \\
\hline F-6 & 0.045 & 0.9133 & 0.00115 & 0.9895 & 2.2844 & 0.9834 & 0.5041 & 0.0285 & 0.9774 \\
\hline
\end{tabular}

Table 6: Steady State flux $\left(J_{s s}\right)$ and Permeability Coefficient $\left(K_{p}\right)$ data of various formulations (F-1 to F-6)

\begin{tabular}{|c|c|c|}
\hline $\begin{array}{c}\text { Formulation } \\
\text { Code }\end{array}$ & $\begin{array}{c}\text { Steady State Flux }\left(\mathbf{J}_{\text {ss }}\right) \\
\left(\text { mcg.cm }^{-2} \cdot \mathbf{h r}^{-1}\right) \\
\text { Mean } \pm \text { S.D. }\end{array}$ & $\begin{array}{c}\text { Permeability Coefficient }\left(\mathrm{K}_{\mathrm{p}}\right) \\
\left(\mathrm{cm} . \mathrm{hr}^{-1}\right) \times \mathbf{1 0}^{-3} \\
\text { Mean } \pm \text { S.D. }\end{array}$ \\
\hline F-1 & $0.101 \pm 0.007$ & $0.431 \pm 0.02$ \\
\hline F-2 & $0.101 \pm 0.006$ & $0.457 \pm 0.004$ \\
\hline F-3 & $0.120 \pm 0.002$ & $0.476 \pm 0.002$ \\
\hline F-4 & $0.102 \pm 0.006$ & $0.472 \pm 0.007$ \\
\hline F-5 & $0.210 \pm 0.001$ & $0.881 \pm 0.003$ \\
\hline F-6 & $0.102 \pm 0.004$ & $0.44 \pm 0.009$ \\
\hline
\end{tabular}

\section{Scanning Electron Microscopy (SEM):}

Photomicrograph (Figure 1) represents the SEM of blank transdermal film, Carvedilol loaded transdermal film before permeation and Carvedilol loaded transdermal film after permeation study of F5 patches respectively. The scanning electron micrographs of the drug loaded film clearly indicated that Carvedilol was molecularly dissolved in the polymer matrix (figure 1). After completing the permeation study the film (figure 1) showed the presence of pores/channels and which indicating the drug permeation was diffusion controlled across rat epidermis.

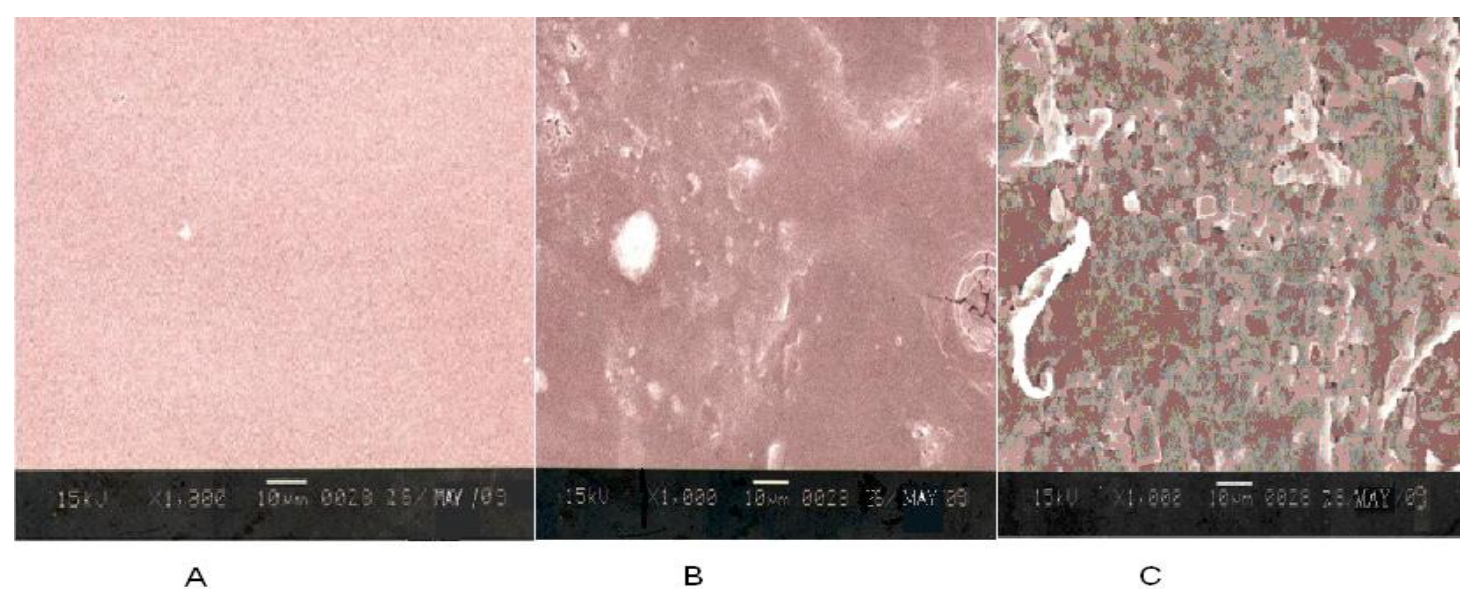

Figure 1: Scanning Electron Microscopy (SEM) of blank \& F-5 transdermal patches: A: SEM of Blank Transdermal Film (Without Drug); B: SEM of Carvedilol Loaded Transdermal Film (F-5) before Carrying out the Permeation Study \& C: SEM of Carvedilol Loaded Transdermal Film (F-5) after Carrying out the Permeation Study. 


\section{Primary Skin Irritancy Study:}

The skin irritation test of the formulated patches were carried out in comparison with standard and irritant; formalin $(0.8 \%)$. It was carried out by visual observation with the help of visual scoring scale. Transdermal patches F-3 and F-5 were subjected to skin irritation studies. The results showed that F-3 and F-5 formulations produced negligible signs of erythema, edema or ulceration on the skin of albino rabbits after 7 days. According to some researchers ${ }^{15-19}$, compounds producing scores of 2 or less are considered negative (no skin irritation). Hence, the developed transdermal formulations were free of skin irritation. On the other hand, standard irritant, formalin produced severe erythema and edema. These results indicate that drug does not produce any cutaneous reaction and transdermal patches are well tolerated by the subjects.

\section{Drug-Excipient Interaction Studies:}

The possible drug-excipient interaction study was studied by FTIR spectroscopy and DSC of different formulations (F-3 and F-5).

\section{Fourier Transform Infrared Spectroscopy:}

In the IR spectra of formulations of F-3 and F-5 the major peaks responsible for functional groups like $-\mathrm{OH}$, $\mathrm{N}-\mathrm{H}, \mathrm{C}-\mathrm{N}$ and C-O-C of Carvedilol slightly altered that may be due to formation of weak hydrogen bonding with polymers and other excipients and that was further confirmed by DSC studies.

\section{Differential Scanning Calorimetry:}

The DSC analysis (figure 2)of pure Carvedilol showed a sharp exothermic peak at $120.99^{\circ} \mathrm{C}$ corresponding to its melting point of $110^{\circ} \mathrm{C}$ but in case of final formulations ( F-3 and F-5) it was changed slightly as shown in figure 3 and 4 , may be due to weak hydrogen bonding with polymers and other excipients. Although in vitro permeation data concluded that it did not seem to interfere with the drug permeation from the transdermal patches and drug was also in a stable form within the patches.

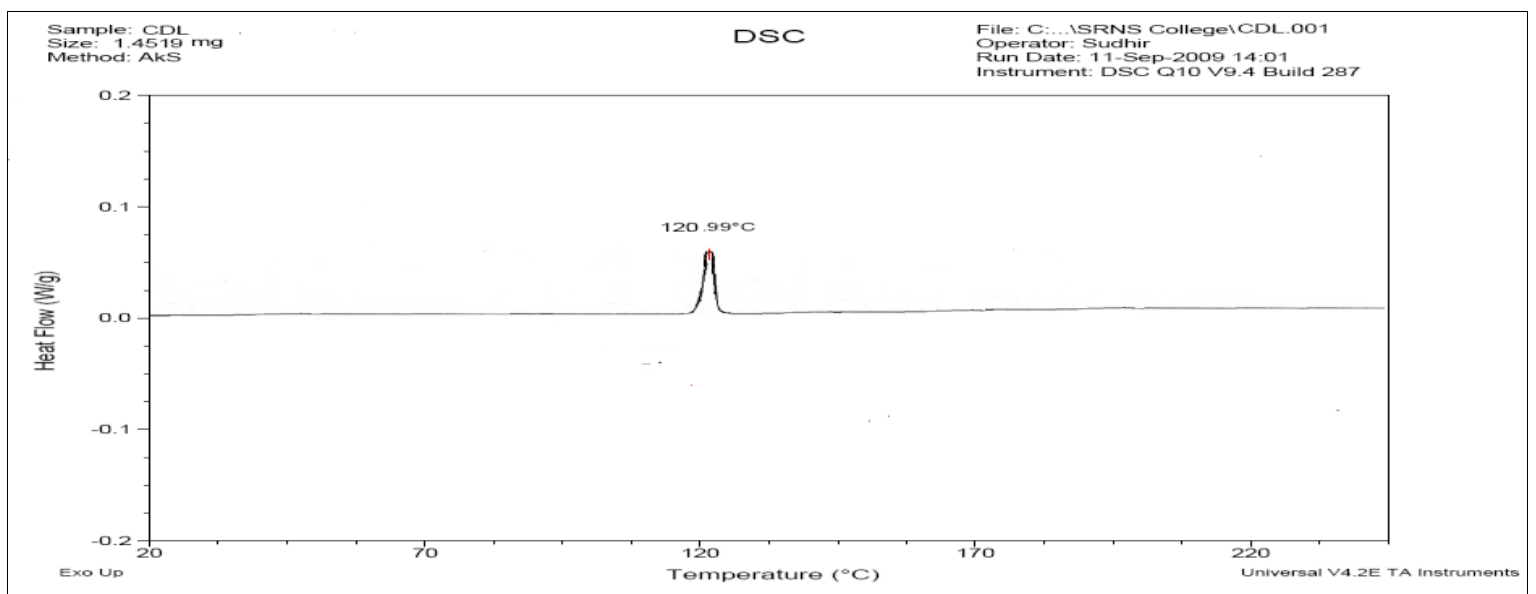

Figure 2: DSC Thermogram of physical mixtures of Carvedilol (CDL), EC and HPMC K15 M.

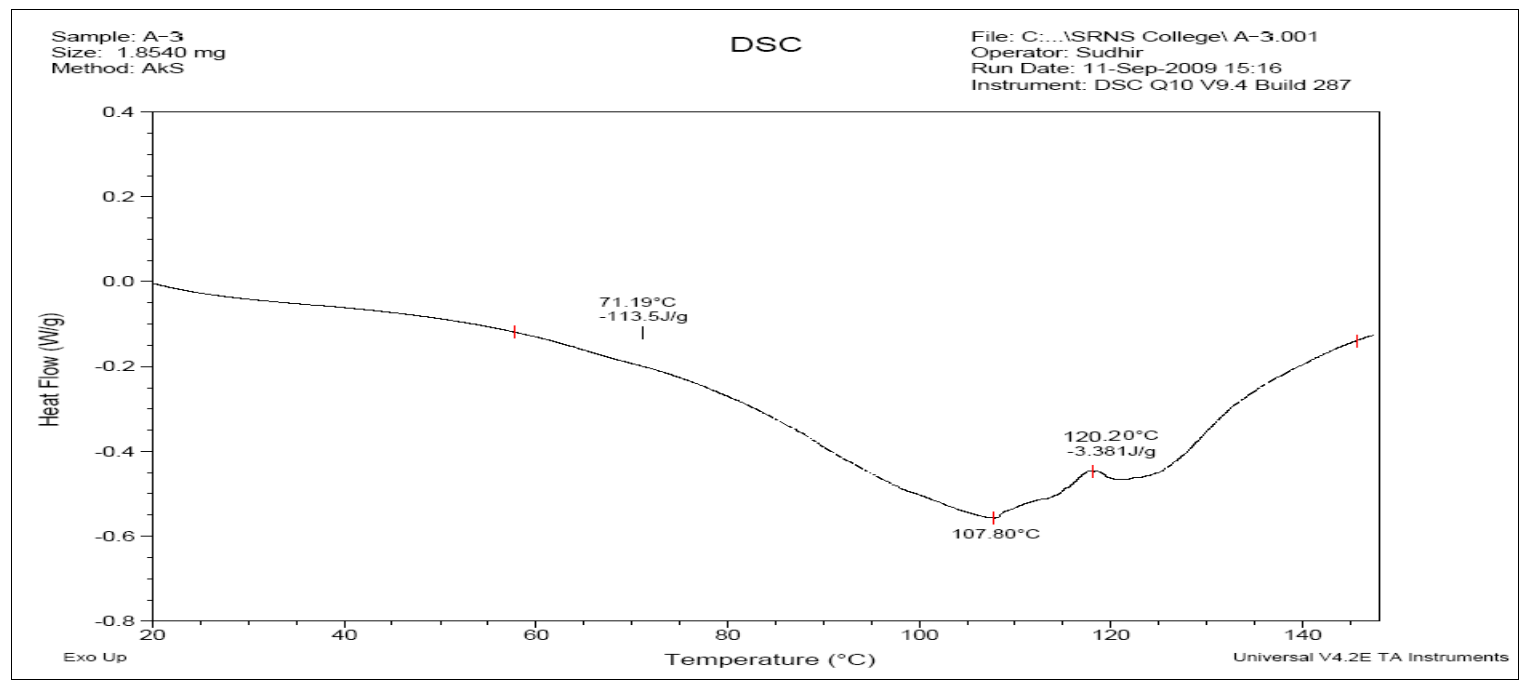

Figure 3: DSC Thermograms of F-3 Formulation composed by CDL, EC and HPMC K15M. 


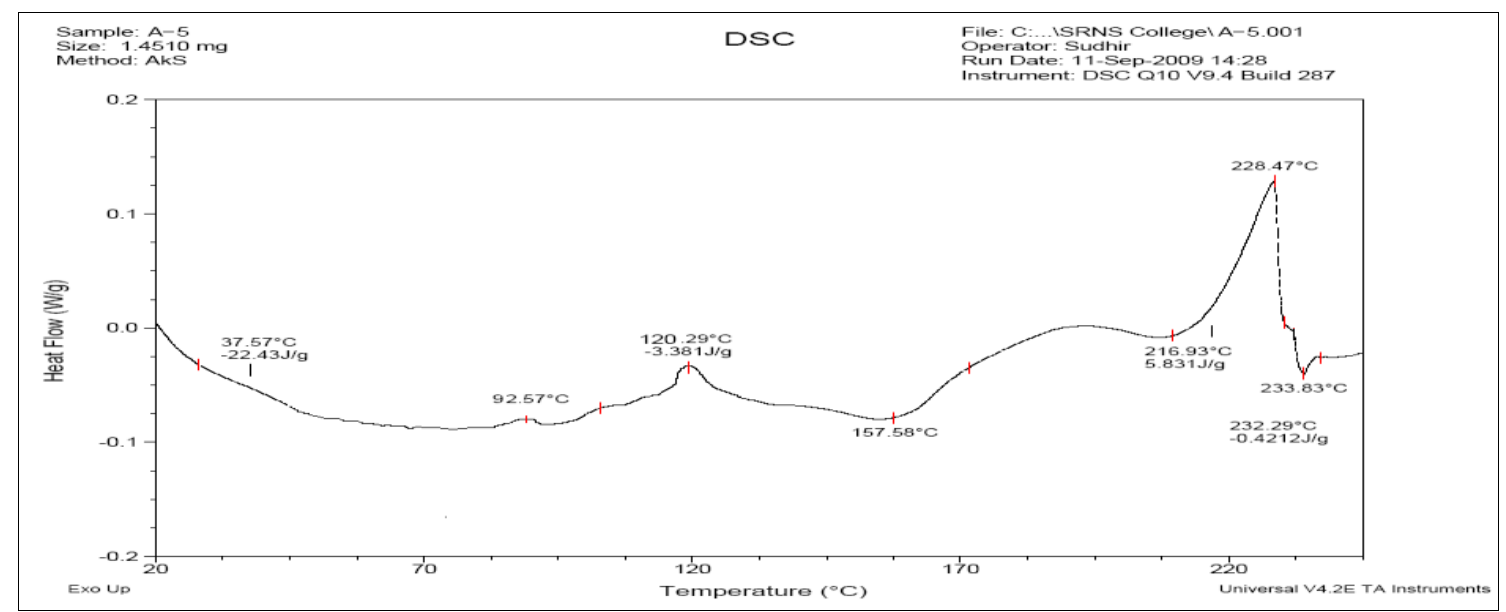

Figure 4: DSC Thermograms of F-5 Formulation Composed of CDL, EC and Carbopol-934.

\section{X-Ray Diffraction study:}

$X$-ray diffraction study was carried out to reveal the crystalline modifications after the preparation of patches. Results of $x$-ray diffractograms for F-3 and F-5 formulations were studied and compared in respect of crystalline modifications with physical mixtures of ECHPMC K15M-CDL (PM-1) and EC-CP 934-CDL (PM2) respectively. It was shown in figure 5. According to diffractograms it was concluded that pure CDL which having crystalline form due to more no of peaks, but in case of physical mixtures (PM-1 and PM-2) prepared in a same ratio of polymers and drugs, shown $2 \theta$ values $32.8854,41.8848,43.4429,48.9334$ and 32.9052, 41.8953, 43.4426, 48.9359 receptively. These prominent peaks were not observed in transdermal patches of $(\mathrm{F}-3$ and F-5), and it may be suppressed due to change of the amorphous form.

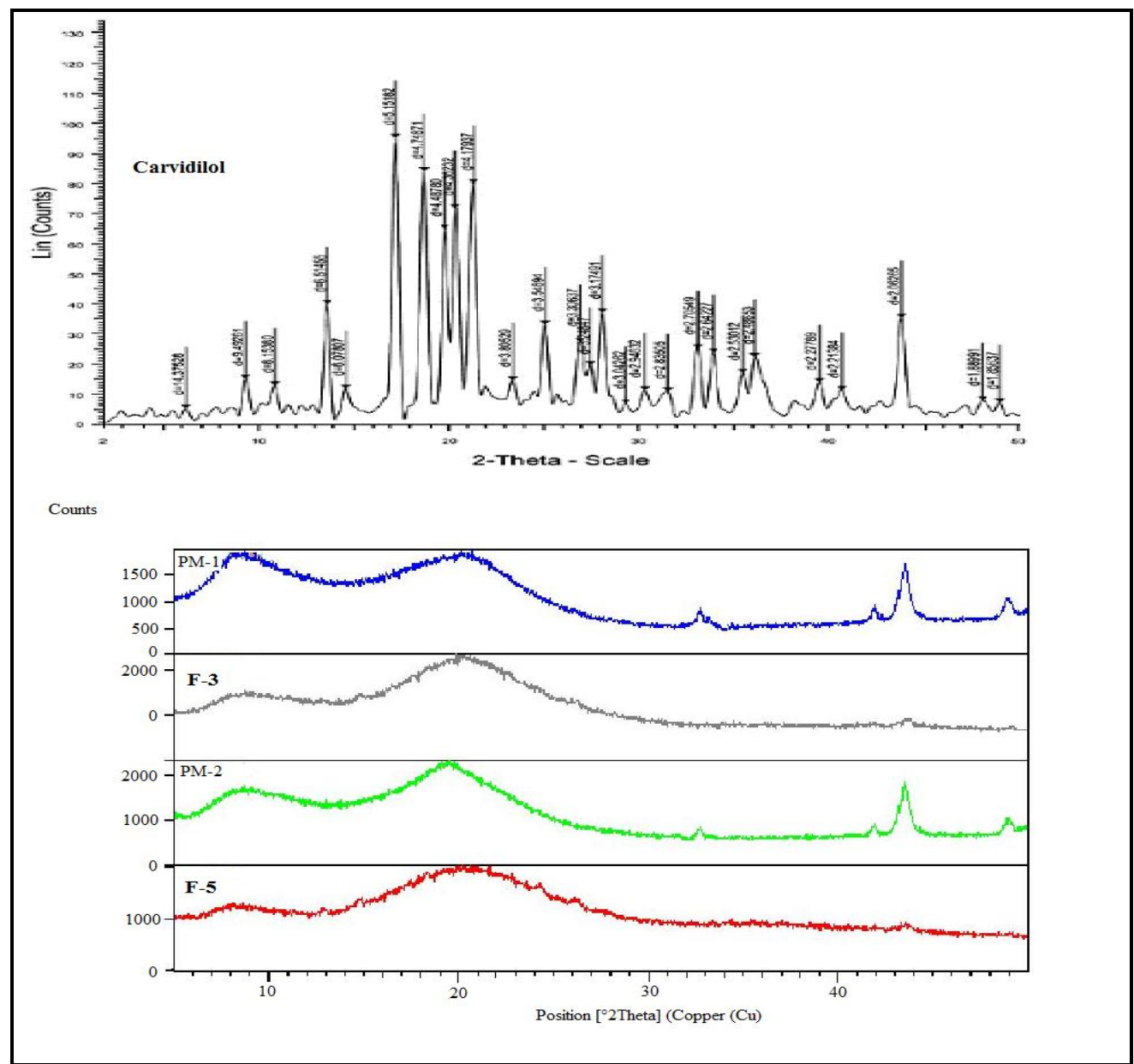

Figure 5: XRD of pure drug CDL, two Best formulations (F-3, F-5) and Corresponding Physical Mixtures (PM1, PM-2), F-3; CDL: EC: HPMC K15 M, F-5; CDL: EC: Carbopol 934, PM-1; CDL: EC: HPMC K15 M, PM-2; CDL: EC: Carbopol- 934. 


\section{Stability Study of the Best Formulation:}

An accelerated stability study contains results regarding remaining drug content and physical appearance of best formulation i.e. F-5 which concluded that R.D.C. of F-5 formulation was ranged between $0.227 \pm 0.022$ to $0.219 \pm 0.045$ and physical appearance was also good at $4{ }^{\circ} \mathrm{C}$ and $45^{\circ} \mathrm{C}$ up to 30 days except in case of $60^{\circ} \mathrm{C}$. At $60^{\circ} \mathrm{C}$ the physical appearance was good up to 15 days after that film was found hard, rigid and brittle. From stability data it was calculated that the shelf life of the F5 formulation was 328.50 days at $25^{\circ} \mathrm{C}$. It is therefore preferable to store the patches in the refrigerator.

\section{CONCLUSION}

Transdermal drug delivery system is a most suitable system for a long-term treatment or for a multi dose treatment, because different transdermal patches are prepared for a long period of time in a suitable dose proving treatment from a day to even up to seven days. In this study Carvedilol transdermal patches were prepared with combination of different polymers such as EC: PVP K-30, EC: HPMC K-15M, EC: Carbopol-934. Total six formulations were selected (F-1 to F-6) for further evaluation such as physicochemical properties, in-vitro drug permeation study and surface $\mathrm{pH}$ of the film. From Physicochemical evaluation it is found that thickness, weight variation, moisture content, drug content, folding endurance and flatness were suitable for maximum stability of the prepared transdermal patches. In-vitro drug permeation study, the percent of drug permeated was found to maximum 95.44 and $90.12 \%$ from from F-3 and F-5 film respectively. Based on physicochemical and in-vitro permeation studies; F-3 and F-5 were chosen as the best patches among all the

\section{REFERENCES:}

1. Cho C.W., Shin, S.C., 2004. Enhanced transdermal delivery of atenolol from the ethylene- vinyl acetate matrix. Int. J. Pharm. Sci. 287, 67-71.

2. Nandy B.C., Chourasiya, S.K, Roy S, 2011. Effect of Various Polymers on Carvedilol Transdermal Films: Invitro Permeation Studies. Der Pharmacia Sinica, 2 (4): 203-217.

3. Kydonieous A. F., Brener, B. 1987. "Transdermal Delivery of Drugs”. CRC Press, Baca Raton, p. 3.

4. Monkhouse D.C., Huq, A.S., 1988. Transdermal drug delivery- problems and promises. Drug. Dev. Ind. Pharm. 14, 183.

5. The Merck Index, 1997. An Encyclopedia of Chemical, Drugs, and Biologicals. Merck \& Co. Inc., New Jersey, p. 1923.

6. Vishnu Y.V., Chandrasekhar, K., Ramesh, G., Rao, Y. M. Development of mucoadhesive patches for buccal administration of carvedilol. Curr. Drug Del. 4, 27-39.

7. Goodman \& Gilman's, The Pharmaceutical Basis of Therapeutics, Hardmen J G. 10 th ed., Mc Graw Hill Medical Publishing Division, 1996, 708

8. Jain P.S., Talele, G.S., Talele, S.G., Surana, S.J., 2005. Spectrophotometric determination of carvedilol from bulk and formulations. Ind. J. Pharm. Sci. 67, 358-359.

9. Thimasetty J., Pandey, G.S., Babu, P.R.S., 2008. Design and in vivo evaluation of Carvedilol buccal mucoadhesive patches. Pak. J. Pharm. Sci. 21, 241-248.

10. Ubaidulla U., Reddy M.V.S., Ruckmani, K., Ahmad, F.J., Khar, R.K., 2007. Transdermal therapeutic system of carvedilol: effect of hydrophilic and hydrophobic matrix on in vitro and in vivo characteristics. AAPS Pharm. Sci. Tech. 8, 18. formulations. F-5 was found to have maximum rate of drug permeation, maximum steady state flux and maximum permeability coefficient. Through the SEM analysis the F-5 film showed the presence of pores/channels and it was indicating the diffusion controlled permeation of drug across the rat epidermis. From the FTIR studies it was concluded that Carvedilol slightly altered into the formulated patches and that may be due to formation of weak hydrogen bonding with polymers and other excipients. It was further confirmed by DSC studies. But from in vitro permeation data it can be concluded that it did not seem to interfere with the drug permeation from the transdermal patches and drug was also in a stable form within the patches. According to XRD diffractograms it was concluded that pure CDL was in crystalline form due to more no of peaks. In case of physical mixtures (PM-1 and PM-2) prepared in a same ratio of polymers and drugs , showed $2 \theta$ values $32.8854,41.8848,43.4429,48.9334$ and 32.9052, $41.8953,43.4426,48.9359$ receptively. The major peaks were disappeared in transdermal patches of F-3 and F-5 and it may be suppressed due to changes of the polymorphic amorphous form. According to primary skin irritancy study, results indicated that drug did not produce any cutaneous reaction and transdermal patches are well tolerated by the subjects. The stability study concluded that the shelf life of the F-5 formulation was 328.50 days at $25^{\circ} \mathrm{C}$. It is therefore preferable to store the film in the refrigerator. In view of the encouraging results obtained, further clinical studies can be carried out using the best obtained formulation on healthy human volunteers.

11. Tanwar Y. S., Chauhan, C.S., Sharma, A. Development and evaluation of carvedilol transdermal patches. Acta Pharm. 57,151-159.

12. Arora P., Mukharjee, B., 2002. Design, development physicochemical, and in vitro and in vivo evaluation of transdermal patches containing diclofenac diethylammonium salt. J. Pharm. Sci. 91, 2076-2089.

13. Mundargi R.C. and Patil, S.A., 2007. Evaluation and controlled release characteristics of modified Xanthan films for transdermal delivery of Atenolol. Drug Dev. Ind. Pharm. 33, 79-90.

14. Kanikkannan N., Andega, S., Burton, S., Babu, J., Singh, M., 2004. Formulation and in vitro evaluation of transdermal patches of melatonin. Drug Dev. Ind. Pharm. 30, 205-212.

15. Moffat A.C., 1986. "Clarke's Isolation and Identification of Drugs in Phamaceuticals, Body Fluids and Post- Portem Material". Pharmaceutical Press, London,

16. Vickers C.H.F., 1963. Existence of reservoir in the stratum corneum. Arch. Deramatol. 88, 20-23.

17. Mutalik S., Udupa, N., 2004. Glibenclamide transdermal patches: physicochemical, pharmacodynamic, and pharmacokinetic evaluation. J. Pharm. Sci. 93, 1577-1592.

18. Devi V. K., Saisivam, S., Maria, G. R., Deepti, P. U., 2003. Design and Evaluation of Matrix Diffusion Controlled Transdermal Patches of Verapamil Hydrochloride. Drug Dev. Ind. Pharm. 29, 495-503.

19. Murthy S.N., Rani, S., Hiremath, R., 2001. Formulation and evaluation of controlled-release transdermal patches of theophylline-salbutamol sulfate. Drug Dev. Ind. Pharm. 27, 1057-1062. 


\section{This page is intentionally left blanked}

